\title{
Mini-Review
}

Fetal Diagnosis and Therapy
Fetal Diagn Ther 2011;29:117-126

DOI: $\underline{10.1159 / 000321346}$
Received: September 13, 2010

Accepted: September 20, 2010

Published online: November 17, 2010

\section{Imaging of Fetal Cytomegalovirus Infection}

\author{
Gustavo Malinger ${ }^{a, d}$ Dorit Lev ${ }^{b, d}$ Tally Lerman-Sagiec, ${ }^{c}$ \\ ${ }^{a}$ Fetal Neurology Clinic, Department of Obstetrics and Gynecology, ${ }^{b}$ Fetal Neurology Clinic, Genetics Institute, \\ and ${ }^{\mathrm{C} F e t a l}$ Neurology Clinic, Pediatric Neurology Unit, Wolfson Medical Center, Holon, and ${ }^{\mathrm{d}}$ Sackler School of \\ Medicine, Tel Aviv University, Tel Aviv, Israel
}

\section{Key Words}

Cytomegalovirus · Fetal brain · Fetus • Intrauterine infections · Magnetic resonance imaging • Ultrasound

\begin{abstract}
Fetuses with congenital cytomegalovirus infection may remain asymptomatic or present with a wide range of brain pathologies. These findings are not always obvious but may on some occasions be demonstrated by ultrasound and $\mathrm{MRI}$, they include ventriculomegaly, microcephaly, increased periventricular echogenicity, calcifications, periventricular pseudocysts, intraventricular synechia, malformations of cortical development, cerebellar lesions and T2 abnormal temporal signals. The purpose of this mini-review is to describe US and MRI findings characteristic of congenital cytomegalovirus infection, with particular emphasis on their time of appearance, frequency and specificity.
\end{abstract}

Copyright $\odot 2010$ S. Karger AG, Basel

\section{Introduction}

The clinical spectrum of congenital cytomegalovirus (CMV) infection is vast, ranging from a complete lack of symptoms to severe disease with multiorgan involvement and mental retardation. The prevalence of neonatal disease is unknown and probably varies from country to country. According to United States data, $0.2-2 \%$ of neonates are born with CMV [1]. Most of them are asymptomatic, but $10-25 \%$ will be born with symptoms of diverse severity $[2,3]$.

Affected children can be diagnosed during pregnancy or in the early neonatal period due to the presence of clinical, laboratory and imaging findings characteristic of congenital CMV [4-7]. The presence of microcephaly and/or the imaging of intracranial anomalies in infected children carry a dire neurodevelopmental prognosis $[7,8]$.

Routine screening programs have not been implemented since they are not considered cost effective; therefore, the only chance of prenatal diagnosis of congenital CMV relies on the fortuitous demonstration of CMV signs during routine US examinations. These US findings are not always present at the time of the second-trimester anatomy examination or may not be initially interpreted as suggestive of congenital CMV infection.

Affected fetuses usually, but not always, present with more than 1 imaging finding. The identification of any of the features discussed in the following sections should prompt a detailed search for the other findings. This is particularly true in fetuses with small, or relatively small, head circumferences.

\section{KARGER}

Fax +4161306 1234

E-Mail karger@karger.ch

www.karger.com
(C) 2010 S. Karger AG, Basel

$1015-3837 / 11 / 0292-0117 \$ 38.00 / 0$

Accessible online at:

www.karger.com/fdt
Gustavo Malinger, MD

Department of Obstetrics and Gynecology

Wolfson Medical Center

PO Box 5, Holon 58100 (Israel)

Tel. +972 543010 150, Fax +972 35028 168, E-Mail gmalinger@ gmail.com 
The purpose of this mini-review is to describe US and MRI findings characteristic of congenital CMV infection, with particular emphasis on their time of appearance, frequency and specificity.

\section{Ventriculomegaly}

Ventriculomegaly is a common feature of congenital CMV infection in children. de Vries et al. found mild to moderate ventriculomegaly in 10 of 11 symptomatic children [9].

Ventriculomegaly of different degrees of severity is frequently diagnosed during fetal life and has multiple etiologies, including CMV infection (fig. 1, 2).

In 1991, Drose et al. found fetal hydrocephalus in 3 of 10 fetuses with CMV infection [10]. In 1993, Twickler et al. reported the presence of ventriculomegaly in 2 affected fetuses, in these patients the head circumference was in the microcephalic range and postnatal imaging demonstrated lissencephaly [11]. Lipitz et al. found that only 2 of 9 fetuses with US signs of congenital CMV infection demonstrated ventriculomegaly [12]. Enders et al. studied 189 patients (141 with abnormal serology and 48 with US signs suggestive of CMV). US abnormalities were evident in 39 of 57 cases with proven intrauterine transmission and $50 \%$ of them had ventricular dilatation (11 hydrocephalus, 7 mild ventriculomegaly) [13].

Picone et al. compared the US and MRI findings in 38 fetuses with proven CMV infection [14]. The examinations were performed within 1 week at a mean gestational age of 33 weeks (range 24-37). Of 27 fetuses with abnormal US findings, US depicted ventriculomegaly/lateral ventricle dilatation in 9 while MRI diagnosed this condition in 14. In a similar study, Benoist et al. examined 49 fetuses at a mean gestational age of CMV diagnosis of 31 weeks (range 27-38), and found cerebral lesions in 19. Ventriculomegaly was present in 9 and $5 \mathrm{fe}-$ tuses by the time of the US and MRI examinations, respectively [15].

In an early report from our group on the prenatal brain spectrum of CMV infection, we found ventriculomegaly in 5 of 8 affected fetuses [4]. Fetuses with ventriculomegaly were identified at a more advanced gestational age than those without ventriculomegaly [whole group mean gestational age 27.5 weeks (range 22-37); normal ventricular width group 24.3 weeks (range $22-$ 26); ventriculomegaly group 28.6 weeks (range 22-27)]. All fetuses with ventriculomegaly had associated findings.

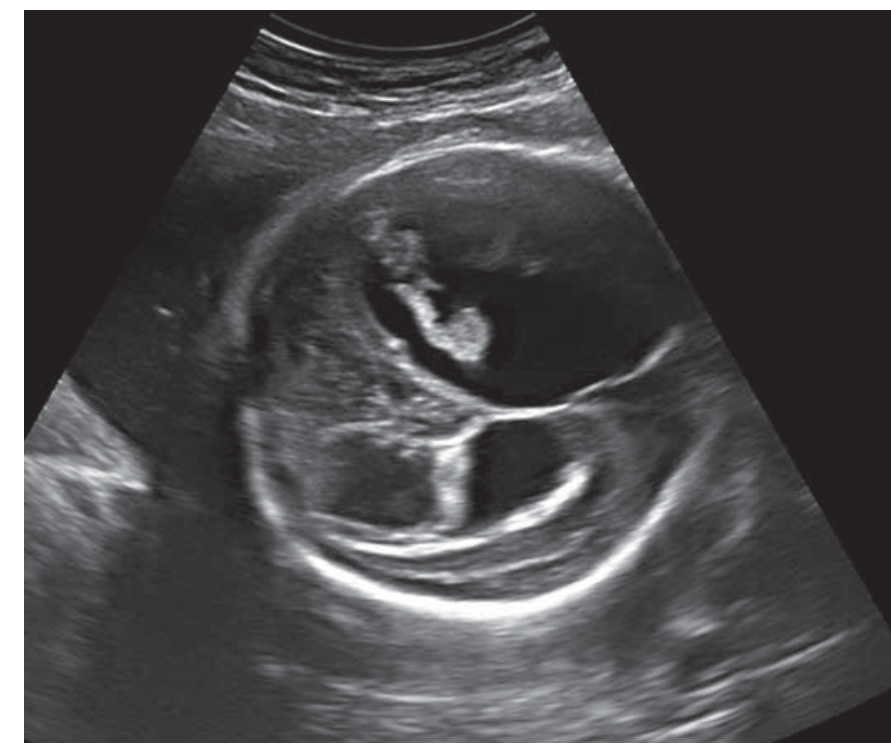

Fig. 1. Severe asymmetric hydrocephalus at 30 weeks of gestation. Axial transabdominal plane shows a more dilated proximal ventricle. Note the 'en plaque' calcification on the border of the distal ventricle. Additional findings (not shown) included head circumference $255 \mathrm{~mm}$ (-1.9 SD), brain parenchyma and cerebellar calcifications, and intraventricular synechia.

The diagnosis of fetal ventriculomegaly and a small head circumference (fig. 1) or microcephaly (fig. 2) should be considered particularly worrisome and prompt a detailed investigation, not only in order to rule out congenital CMV but also chromosomal anomalies or syndromic malformations, particularly malformations of cortical development [16].

\section{Microcephaly}

Microcephaly is characteristic of congenital CMV infection and is associated with a poor prognosis, usually due to mental retardation. Noyola et al. found microcephaly at birth in $19.5 \%$ of the studied population; microcephaly was the most specific predictor for mental retardation (100\%, 95\% CI 84.5-100) and major motor disability $(92.3 \%, 95 \%$ CI 74.8-9) in children with symptomatic congenital CMV infection [8]. Munro et al. in a study based on the Australian National Notification Program, initiated in 1999, reported the clinical symptoms in 62 cases of congenital CMV and found that $22.6 \%$ of these children had microcephaly [17].

The incidence of CMV-related microcephaly in utero ranges from 18.5 to $27.8 \%[14,15]$, but in these reports 

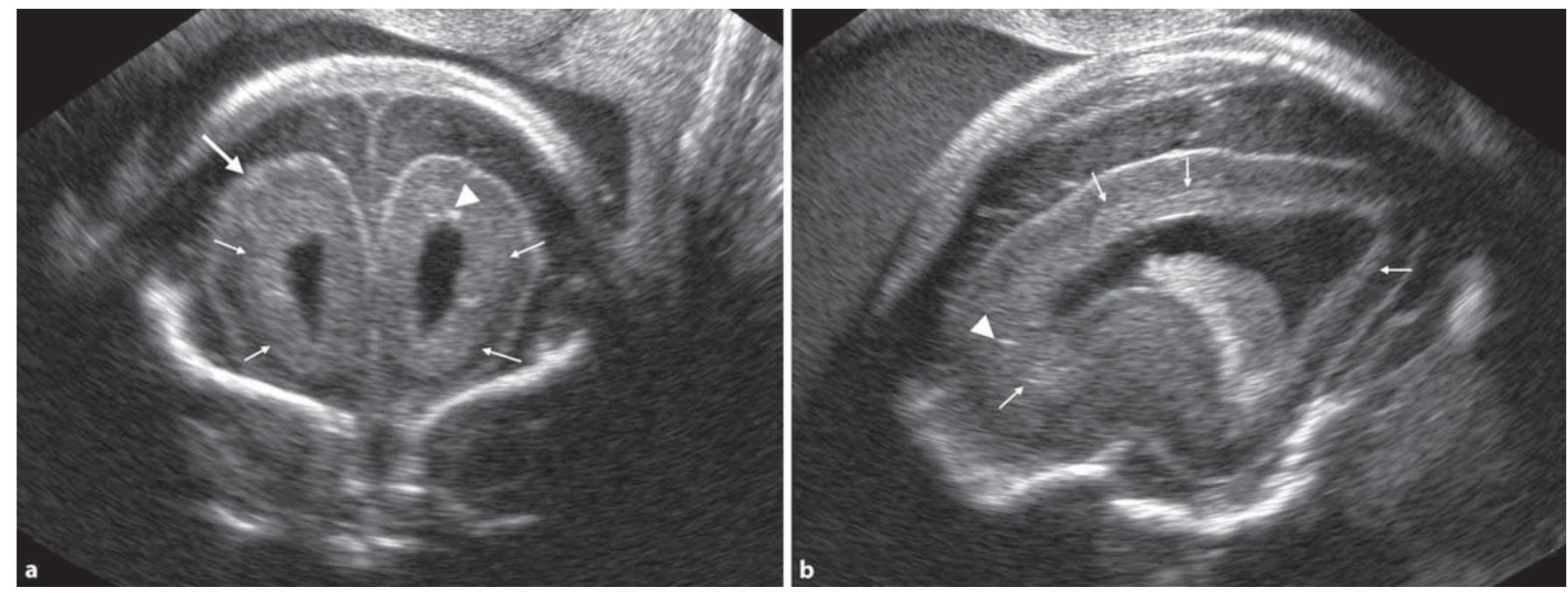

Fig. 2. Mild ventriculomegaly at 22 weeks of gestation. Transvaginal frontal coronal (a) and parasagittal (b) views show enlarged subarachnoidal space due to micrencephaly, periventricular echogenicity (small arrows), parenchymal calcifications (arrowheads) and abnormal cortex consistent with incipient polymicrogyria (large arrow in a). Additional findings (not shown) included dysgenesis of the corpus callosum and possible vermian hypoplasia.

microcephaly was usually only detected after 30 weeks of pregnancy. Most fetuses have other CNS findings associated with the microcephaly. From a total of 10 prenatally diagnosed cases (either by US or MRI), only 1 had isolated microcephaly at birth.

As with ventriculomegaly it should be appreciated that even in severely affected fetuses, microcephaly may not be apparent during the second- or even third-trimester US examinations (fig. 1).

In our practice, we have never diagnosed an infected fetus with isolated microcephaly; the more common associated findings are calcifications, increased periventricular echogenicity and increased extraaxial spaces as the result of brain atrophy (fig. 2).

\section{Increased Periventricular Echogenicity}

Increased echogenicity surrounding the lateral ventricles, representing probable ventriculitis (fig. 2-4), was found in all the patients in our initial description of fetal CMV infection [4]. Since then, others have reported similar findings. Guibaud et al. diagnosed in 3 patients during the third trimester an abnormal, focal, symmetric, bilateral periventricular pattern in the mid-lateral border of the lateral ventricles, including a mainly hyperechogenic lesion [18]. Simonazzi et al. recently reported abnor- mal sonographic brain findings in 8 fetuses at 20-22 weeks of gestation, with a high viral load in the amniotic fluid, 6 had a periventricular echogenic halo [19]. Postmortem examination of the brain was performed in only 2 patients. In one, histological examination demonstrated severe meningoencephalitis, the white matter showed focal periventricular leukomalacia with coagulative necrosis, mineralization, and cellular debris and was partially replaced by sheets of macrophages with mineralization of cells (neurons and glia) and axons. Other zones showed the typical features of telencephalic leukoencephalopathy. Similar, but less severe, findings were found in the other patient.

Simonazzi et al. [19] claim that periventricular echogenicities are only visualized through transvaginal sonography, but we have also depicted this condition using transabdominal probes (fig. 4). Although the authors describe this finding as isolated, careful examination of their published figures reveals in addition the presence of nodular calcifications, mild ventriculomegaly and an irregular ventricular wall.

According to our experience, white matter changes are difficult to visualize during the third trimester due to the progressive development of sulci and gyri and the natural history of these lesions that develop into periventricular cysts and/or calcifications. 

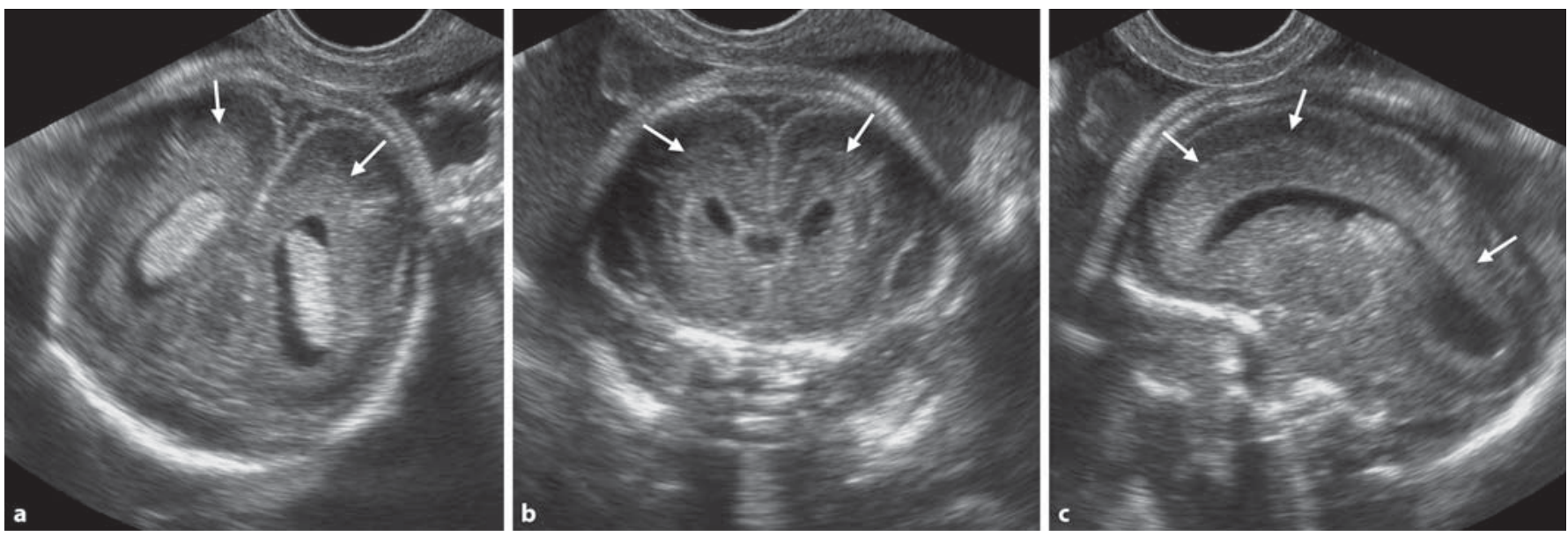

Fig. 3. Isolated periventricular echogenicity at 22 weeks of gestation. Transvaginal axial (a), coronal (b) and parasagittal (c) planes. Note the clear demarcation between the echogenic periventricular zone and the distal portion of the cortex (arrows); this echogenic zone is depicted in all the orthogonal planes.

It should be taken into consideration that not all echogenic halos observed around the ventricles are indicative of CMV infection; true halos should be observed in all studied planes and will rarely or never be found as isolated findings.

It is difficult to compare this hyperechogenic pattern with MRI findings, but it may represent the hyperintense T2-weighted signals described by Prayer et al. in the white matter during the acute and subacute stages of intrauterine infection [20] (see below).

\section{Calcifications}

Brain calcifications are considered the hallmark of intrauterine infections and have been described not only in congenital CMV infection but also in fetuses and children with congenital toxoplasmosis, rubella, herpes simplex and varicella $[21,22]$.

According to a study published by the US CMV registry, calcifications were present in $43 \%$ of the 100 cases reported to the registry during the years 1990 and 1991 [23]. In another report from Australia, calcifications were only found in $21 \%$ of a group of 61 symptomatic children [17].

Two different types of calcifications have been reported in children:

(1) Punctate calcifications. These are small and disseminated and may be present in any part of the brain, including the basal ganglia and the cerebellum.

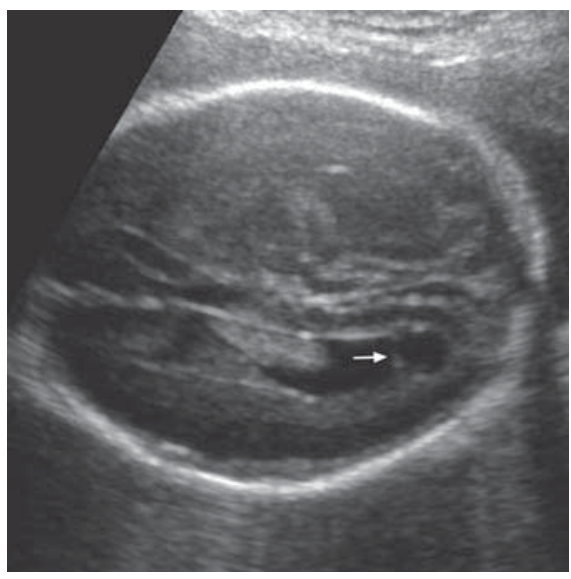

Fig. 4. Increased periventricular echogenicity as demonstrated by transabdominal ultrasound at 22 weeks of gestation in a fetus with proven CMV infection. Note the presence of a periventricular synechia (arrow).

(2) Coarse, 'en plaque' calcifications. These characteristically affect the periventricular zone, are associated with malformations of cortical development and may represent a late stage of the previously discussed increased echogenicity pattern $[24,25]$.

Lenticulostriate vasculopathy as described by BenAmi et al. should not be confused with calcifications and, although initially described in children with congenital CMV infection, it is not considered a specific sign of the disease [26]. Estroff et al. have reported the presence of 

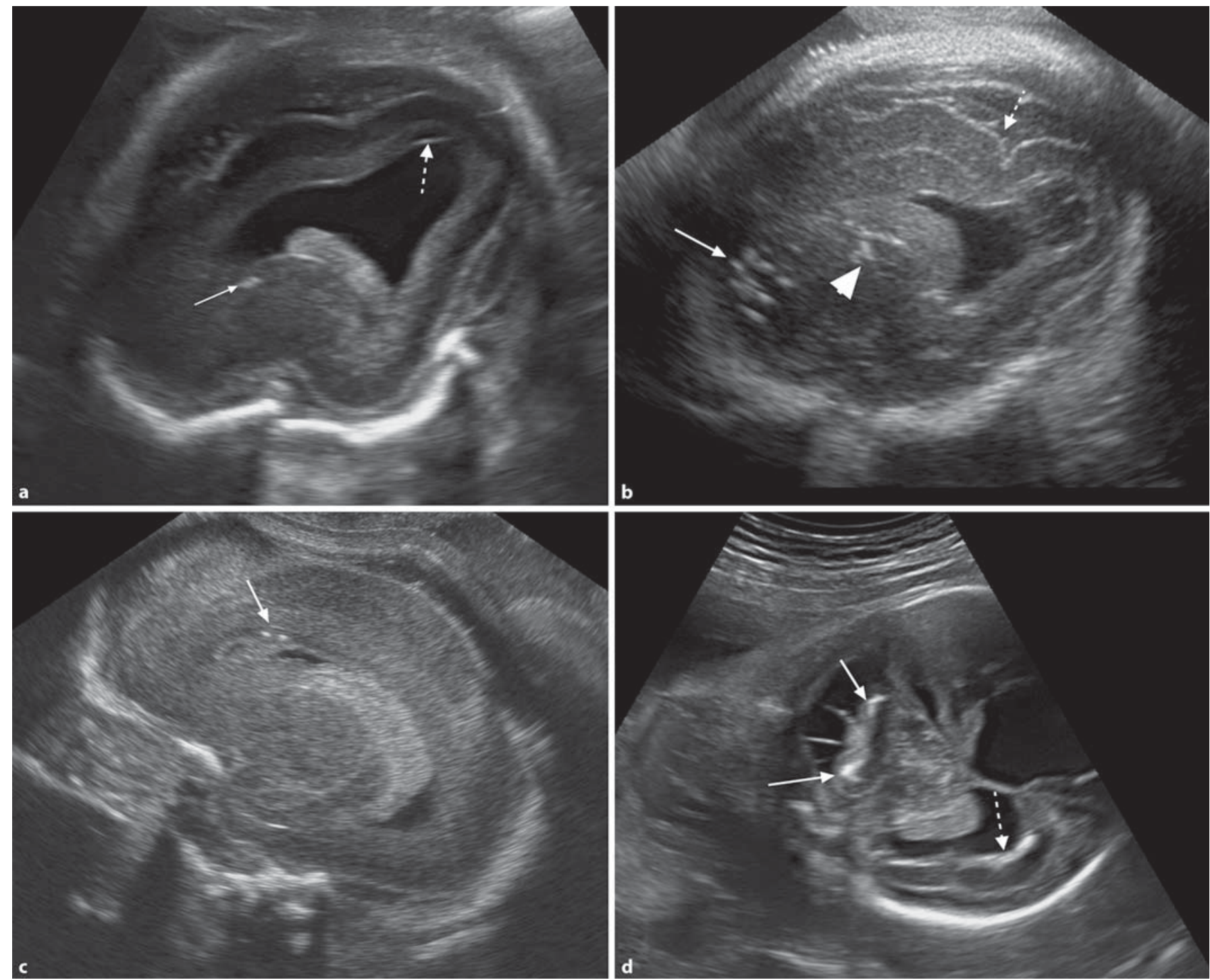

Fig. 5. Calcifications in 4 different fetuses with congenital CMV infection. a 29 weeks of gestation. Single punctate caudate calcification (arrow). Note the occipital periventricular cyst (dashed arrow) and periventricular echogenicity. b 30 weeks of gestation. Multiple punctate calcifications in the frontal brain parenchyma (arrow) and lenticulostriate vasculopathy (arrowhead), associated findings included abnormal sulcation (dashed

branching linear echogenic areas in the thalami of a fetus with CMV infection [27].

Drose et al. using transabdominal US described periventricular calcifications in 2 of 10 fetuses with congenital CMV infections; in another 2 the calcifications were diagnosed only at autopsy [10]. In our early series, using transvaginal US, 8 of 9 fetuses had calcifications, including cerebellar involvement in 1 fetus [4]. arrow) and enlarged subarachnoid space. c 23 weeks of gestation. Two punctate calcifications in the corpus callosum (arrow) in a fetus with normal ventricular size but with intraventricular synechia, callosal dysgenesis and polymicrogyria (same fetus as in fig. 8). d 30 weeks of gestation. Cerebellar (arrows) and periventricular (dashed arrow) calcifications in the same fetus depicted in figure 1 .

In prenatally diagnosed cases the calcifications do not usually have an acoustic shadow and, although they may be found in any portion of the brain, they have particular predilection for the periventricular zone (fig. 1, 5). Recently, we were able to demonstrate calcifications in affected fetuses in other brain sites (fig. 5).

Ultrasound and CT are better than MRI for the demonstration of calcifications [4].

Fetal Diagn Ther 2011;29:117-126 

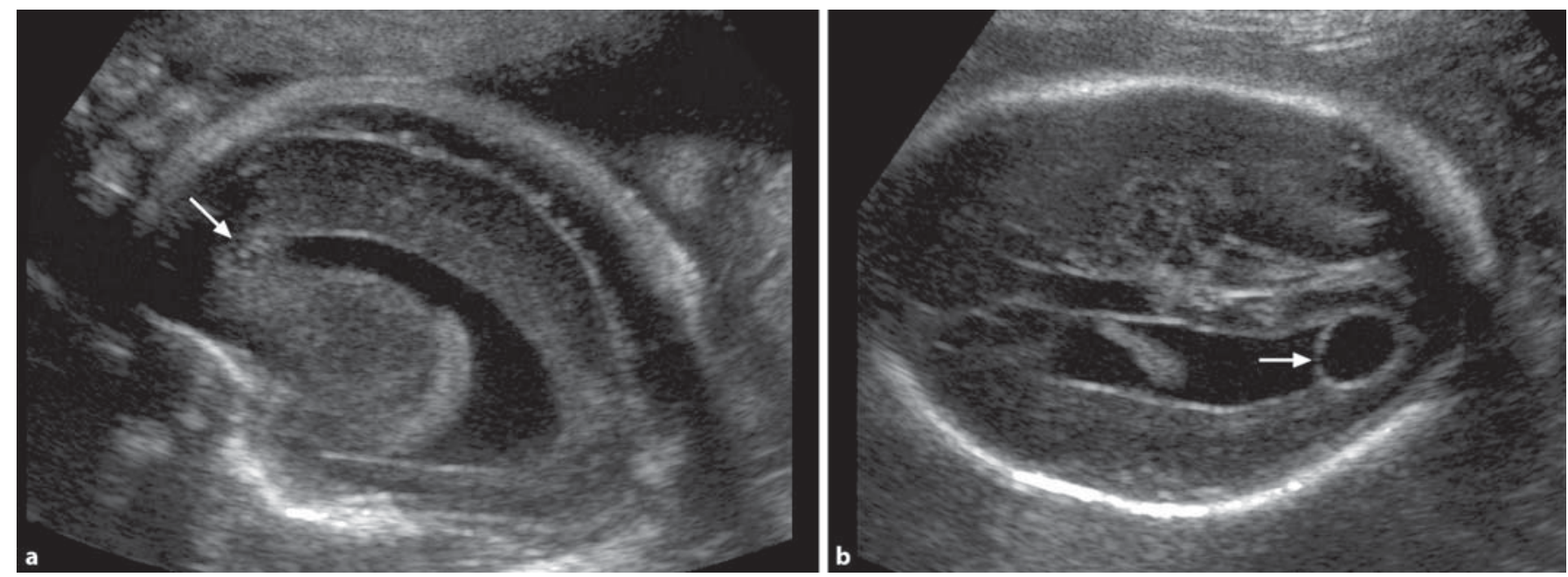

Fig. 6. Periventricular cysts and intraventricular synechia at 27 weeks of gestation. a Transabdominal sagittal plane shows a group of small periventricular cysts close to the frontal horn of the lateral ventricle (arrow). b Transabdominal axial plane in the same fetus shows the formation of a large intraventricular cyst (synechia) in the occipital horn (arrow). This fetus presented with mild ventriculomegaly and normal head circumference.
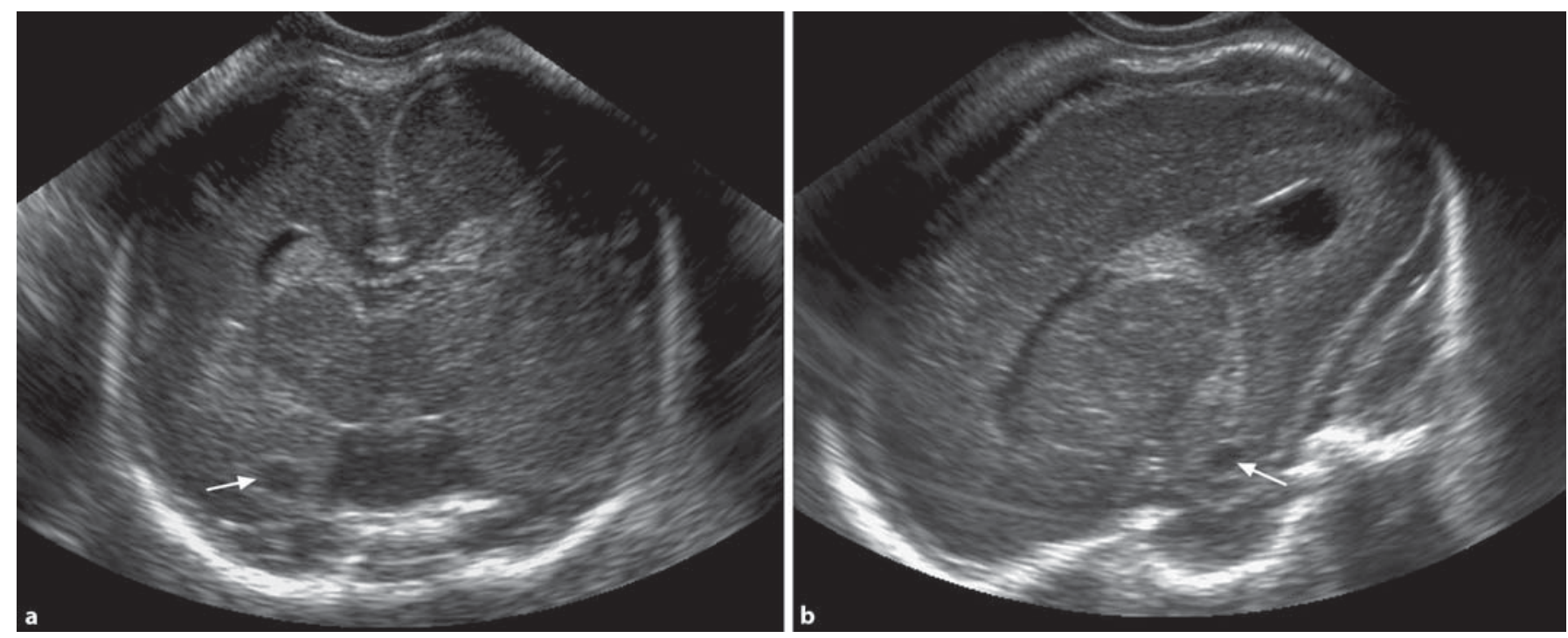

Fig. 7. Temporal periventricular cyst at 28 weeks of gestation. Transvaginal coronal (a) and sagittal (b) planes. The small size of the cyst and its location (arrows) in a region of the brain usually not scanned make its recognition difficult.

\section{Periventricular Pseudocysts and Intraventricular Synechiae}

Periventricular pseudocysts (PVPC) and intraventricular synechiae (IVS) will be described together since they are part of the same pathophysiologial pro- cess. PVPCs occur as the result of necrosis or hemorrhage of the germinal matrix. When the destructive process is substantial and cysts coalesce, the ependyma may separate from the adjacent tissue and develop into IVS (fig. 4, 6). 
PVPCs have been described in association with CMV infection, but they may also be present in cases of chromosomal, metabolic and mitochondrial diseases.

Two pediatric series that were published during the 1990s on the etiology of PVPCs found that CMV was a rare diagnosis in these cases $[28,29]$. In a more recent study that compared US and MRI in symptomatic CMV infected newborns, de Vries et al. were able to visualize the presence of PVPCs in 8 of 11 patients [9]. US depicted occipital or parietal cysts in 4 patients and frontal cysts in 1. MRI was performed in only 6 patients and confirmed the diagnosis in 3 of 3 and depicted the presence of temporal cysts, not visualized by US, in another 3 patients.

The prenatal diagnosis of PVPCs is being reported with increased frequency. Although CMV appears to account for a only a relatively small proportion of fetal cases [30], in the reports on fetuses with CMV the frequency of periventricular cysts is much higher [5]. Picone et al. found PVPCs in 5 of $20 \mathrm{CMV}$-infected fetuses with brain findings; MRI was able to depict 4 that were missed by US [14]. Recently, Doneda et al. described the US and MRI findings in 20 affected fetuses and found subependymal cysts in 4; interestingly, US failed to show any of them [31]. However, it should be noted that the yield of US in diagnosing CMVrelated anomalies was extremely low in this paper.

Temporal cysts may be difficult to diagnose by US since this part of the brain is usually not studied or it may be difficult to differentiate between a cyst and a large temporal horn (fig. 7) [32].

IVS are also common in affected fetuses but rarely as an isolated finding $[33,34]$. They originate from the fusion of adjacent PVPCs and separation of the ependyma from the germinal matrix. IVS are usually found in the occipital horns but may occasionally be present in the temporal horns [31]. According to our experience, they are pathognomonic of CMV infection. IVS are best depicted using axial and sagittal planes and may easily be missed in coronal ones or when the synechia is very large and reaches the choroid plexus.

\section{Malformations of Cortical Development}

Interference with proliferation and migration at critical times, regardless of the etiology, may result in abnormal cortical development. In utero, it is usually diagnosed following the development of microcephaly and/or abnormal sulcation and gyration, frequently associated with commissural dysgenesis [16, 35, 36]. Congenital CMV infection during the late first or early second tri-

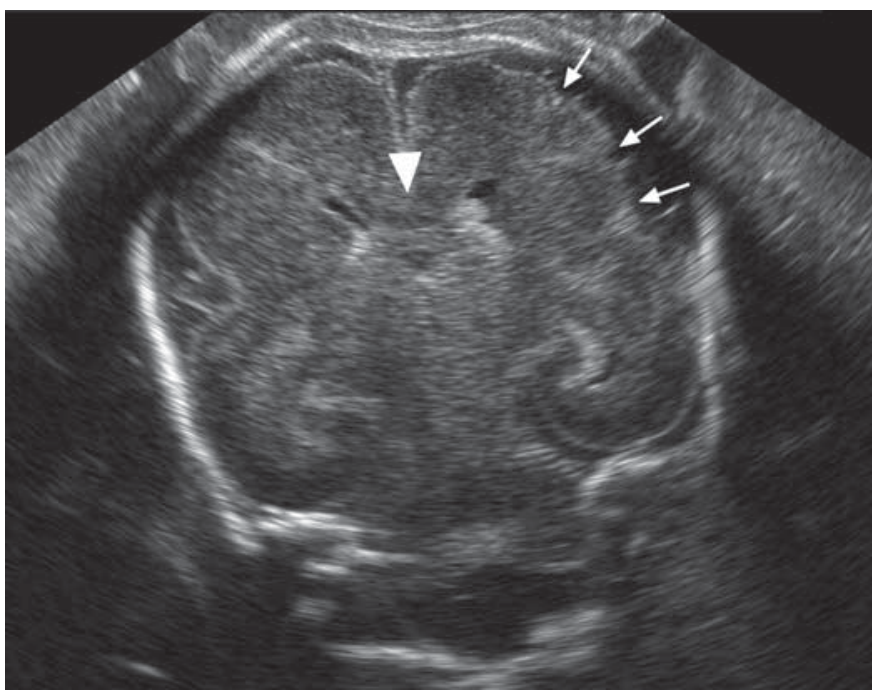

Fig. 8. Malformation of cortical development at 23 weeks of gestation. Modified transvaginal coronal plane at the level of the Sylvian fissure shows abnormal cortex consistent with polymicrogyria (arrows) and callosal dysgenesis (arrowhead). Note the normal pattern of the contralateral Sylvian fissure.

mesters may affect these processes and produce various forms of malformations of cortical development. Following the description of lissencephaly-pachygyria [37], oligo/pachygyria [38], polymicrogyria [9] and schizencephaly $[39,40]$ in children with congenital CMV infection, and improvement in fetal imaging by US and MR, descriptions of malformations of cortical development in fetuses have been published. Our group reported an abnormal sulcation pattern in 4 of 8 affected fetuses; interestingly, 2 of them also had callosal dysgenesis [4]. Histological examination following termination of pregnancy was performed in 3 patients and showed the presence of polymicrogyria in 2 of them. Since then we have diagnosed other fetuses with abnormal sulcation/gyration and/or callosal dysgenesis related to CMV infection (fig. 8). The prenatal diagnosis of these conditions requires a good knowledge of the normal development of the cortex [34, 41]; clues for diagnosis include the presence of early, abnormally developed sulci, overfolded small and superficial sulci or lack of normal sulcation relative to gestational age.

A similar case of polymicrogyria with US and MRI documentation has recently been reported [42]. Callosal dysgenesis as a result of CMV insult should be considered in a fetus with positive serology or when associated with other common CMV signs. 


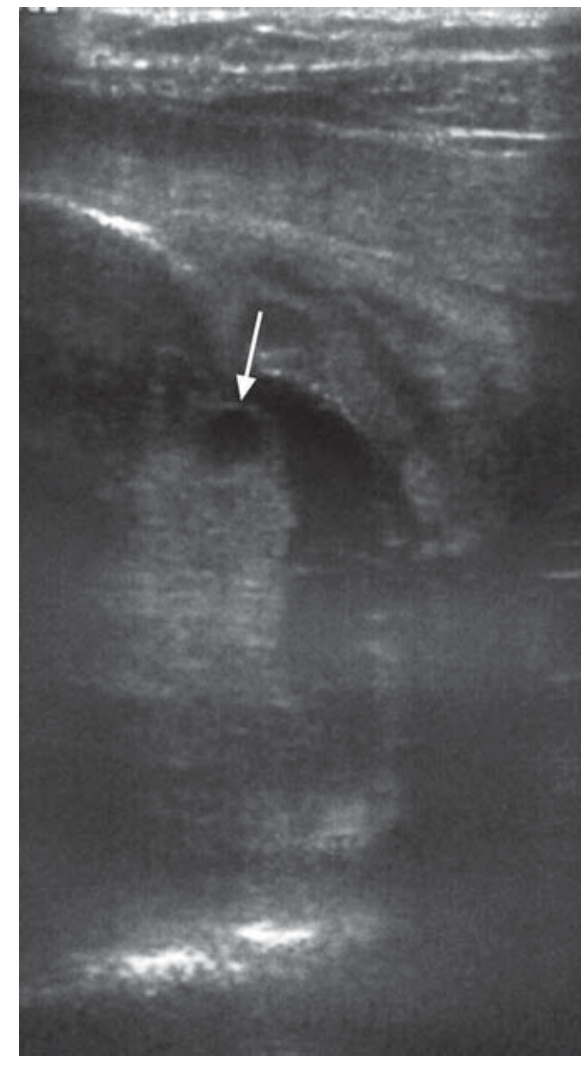

Fig. 9. Cerebellar cyst at 30 weeks of gestation. The cyst involved almost half of the hemisphere (arrow). The fetus presented with coarse, 'en plaque' calcifications, malformations of cortical development and micrencephaly (not shown).

\section{Cerebellar Findings}

CMV may affect the cerebellum in the same fashion as it affects the fetal cerebrum, causing vermian hypoplasia $[4,9,31]$ and on rare occasions cerebellar hemorrhage [43], calcifications (fig. 5d) [4] or cysts (fig. 9).

We are not aware of any case of isolated cerebellar involvement in a fetus with CMV.

\section{T2 Abnormal Temporal Signals}

Picone et al. [14] and Benoist et al. [15] described hyperintense white matter in the temporal lobes depicted by fetal MRI but not by US. They believe that these are manifestations of CMV not visible to US. The significance of isolated T2 hyperintense signals in the white matter of fetuses with known CMV infection and a nor-

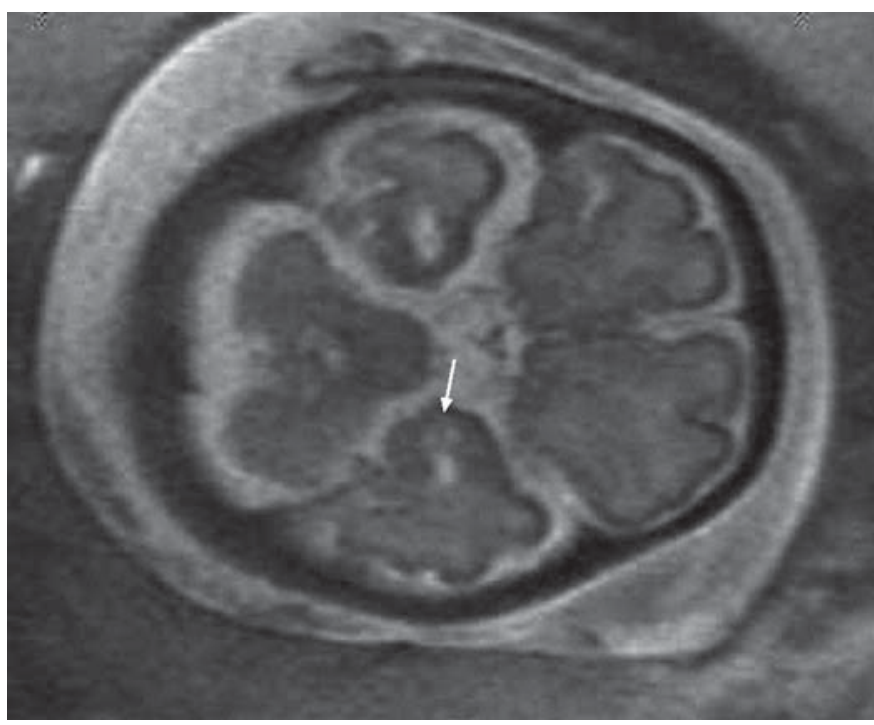

Fig. 10. Periventricular T2 abnormal temporal signals at 35 weeks of gestation. Two small hyperintense lesions are depicted in the temporal area (arrow). Transvaginal US failed to demonstrate the presence of cysts. Normal development at 12 months of age.

mal US examination is still unclear (fig. 10). In a recent study, our group failed to find a relationship between these findings and neurodevelopmental markers [5]. Similar results were recently reported by Lipitz et al. [44]. Doneda et al. described prenatal diagnosis by MRI but not by US of white matter abnormalities of the temporal polar regions. These lesions appeared with a high frequency [37\% (14 of 38 cases)] at the first MRI examination. Among the temporal lesions, dilatation of temporal horns was the earliest anomaly to be recognized, followed by white matter T2-weighted signal hyperintensity and cystic lesions. However, the authors admit that the contribution of the polar temporal lesions to the clinical outcome of patients with congenital CMV infection remains unknown since in 6 of 17 cases who presented with isolated polar temporal lesions, 4 had a normal outcome at ages ranging from 1 day to 2 years, 1 had isolated hearing loss and 1 underwent termination of pregnancy [31].

\section{Searching for Symptomatic Fetal CMV Infection}

In fetuses at risk or when one of the aforementioned findings are detected by a routine US examination, a detailed sonographic evaluation including dedicated neurosonography is indicated with the specific goal of trying 
to demonstrate any other signs of CMV infection. Although most authorities believe that the presence of microcephaly or cranial findings carry a bad prognosis, isolated findings such as periventricular pesudocysts, lenticulostriate echodensities and increased T2 signal in the temporal polar regions on MRI may in certain cases carry a better prognosis.

In fetuses at risk, serial follow-up at 3- to 5-week intervals is necessary to enable diagnosis of late-developing disease.

\section{References}

1 Istas AS, Demmler GJ, Dobbins JG, Stewart JA: Surveillance for congenital cytomegalovirus disease: a report from the national congenital cytomegalovirus disease registry. Clin Infect Dis 1995;20:665-670.

-2 Yinon Y, Farine D, Yudin MH, Gagnon R, Hudon L, Basso M, Bos H, Delisle MF, Menticoglou S, Mundle W, Ouellet A, Pressey T, Roggensack A, Boucher M, Castillo E, Gruslin A, Money DM, Murphy K, Ogilvie G, Paquet C, Van Eyk N, van Schalkwyk J; Fetal Medicine Committee, Society of Obstetricians and Gynaecologists of Canada: Cytomegalovirus infection in pregnancy. J Obstet Gynaecol Can 2010;32:348-354.

3 Kenneson A, Cannon MJ: Review and metaanalysis of the epidemiology of congenital cytomegalovirus (CMV) infection. Rev Med Virol 2007;17:253-276.

4 Malinger G, Lev D, Zahalka N, Ben-Aroia Z, Watemberg N, Kidron D, Ben-Sira L, Lerman-Sagie T: Fetal cytomegalovirus infection of the brain: the spectrum of sonographic findings. AJNR Am J Neuroradiol 2003; 24:28-32.

5 Malinger G, Lerman-Sagie T: Fetal cytomegalovirus infection: the brain as a window in the establishment of prognosis; in Ramenghi A, Evrard P, Mercuri E (eds): Mariani Foundation Paediatric Neurology. Perinatal Brain Damage: From Pathogenesis to Neuroprotection. Montrouge, John Libbey Eurotext, 2008.

6 Pass RF, Fowler KB, Boppana SB, Britt WJ, Stagno S: Congenital cytomegalovirus infection following first trimester maternal infection: symptoms at birth and outcome. J Clin Virol 2006;35:216-220.

7 Ancora G, Lanari M, Lazzarotto T, Venturi V, Tridapalli E, Sandri F, Menarini M, Ferretti E, Faldella G: Cranial ultrasound scanning and prediction of outcome in newborns with congenital cytomegalovirus infection. J Pediatr 2007;150:157-161.

8 Noyola DE, Demmler GJ, Nelson CT, Griesser C, Williamson WD, Atkins JT, Rozelle J, Turcich M, Llorente AM, Sellers-Vinson S, Reynolds A, Bale JF Jr, Gerson P, Yow MD; Houston Congenital CMV Longitudinal Study Group: Early predictors of neurodevelopmental outcome in symptomatic congenital cytomegalovirus infection. J Pediatr 2001;138:325-331.
-9 de Vries LS, Gunardi H, Barth PG, Bok LA, Verboon-Maciolek MA, Groenendaal F: The spectrum of cranial ultrasound and magnetic resonance imaging abnormalities in congenital cytomegalovirus infection. Neuropediatrics 2004;35:113-119.

10 Drose JA, Dennis MA, Thickman D: Infection in utero: US findings in 19 cases. Radiology 1991;178:369-374.

11 Twickler DM, Perlman J, Maberry MC: Congenital cytomegalovirus infection presenting as cerebral ventriculomegaly on antenatal sonography. Am J Perinatol 1993; 10: 404-406.

12 Lipitz S, Yagel S, Shalev E, Achiron R, Mashiach S, Schiff E: Prenatal diagnosis of fetal primary cytomegalovirus infection. Obstet Gynecol 1997;89:763-767.

13 Enders G, Bäder U, Lindemann L, Schalasta G, Daiminger A: Prenatal diagnosis of congenital cytomegalovirus infection in 189 pregnancies with known outcome. Prenat Diagn 2001;21:362-377.

14 Picone O, Simon I, Benachi A, Brunelle F, Sonigo P: Comparison between ultrasound and magnetic resonance imaging in assessment of fetal cytomegalovirus infection. Prenat Diagn 2008;28:753-758.

15 Benoist G, Salomon LJ, Mohlo M, Suarez B, Jacquemard F, Ville Y: Cytomegalovirus-related fetal brain lesions: comparison between targeted ultrasound examination and magnetic resonance imaging. Ultrasound Obstet Gynecol 2008;32:900-905.

16 Malinger G, Kidron D, Schreiber L, Ben-Sira L, Hoffmann C, Lev D, Lerman-Sagie T: Prenatal diagnosis of malformations of cortical development by dedicated neurosonography. Ultrasound Obstet Gynecol 2007;29: 178-191.

17 Munro SC, Trincado D, Hall B, Rawlinson WD: Symptomatic infant characteristics of congenital cytomegalovirus disease in Australia. J Paediatr Child Health 2005;41:449452.

18 Guibaud L, Attia-Sobol J, Buenerd A, Foray P, Jacquet C, Champion F, Arnould P, Pracros JP, Golfier F: Focal sonographic periventricular pattern associated with mild ventriculomegaly in foetal cytomegalic infection revealing cytomegalic encephalitis in the third trimester of pregnancy. Prenat Diagn 2004;24:727-732.
19 Simonazzi G, Guerra B, Bonasoni P, Pilu G, Lazzarotto T, Santini D, Rizzo N: Fetal cerebral periventricular halo at midgestation: an ultrasound finding suggestive of fetal cytomegalovirus infection. Am J Obstet Gynecol 2010;202:599, e591-e595.

20 Prayer D, Kasprian G, Riberiro V, Brugger P, Malinger G: Infections of the fetal brain; in Naidich TP, Castillo M, Cha S, Raybaud C, Smirniotopoulos J (eds): Imaging of the Brain. Amsterdam, Elsevier, 2010.

21 Bailao LA, Osborne NG, Rizzi MC, BonillaMusoles F, Duarte G, Bailao TC: Ultrasound markers of fetal infection. Part 1: viral infections. Ultrasound Q 2005;21:295-308.

22 Bailao LA, Osborne NG, Rizzi MC, BonillaMusoles F, Duarte G, Bailao TC: Ultrasound markers of fetal infection. Part 2: bacterial, parasitic, and fungal infections. Ultrasound Q 2006;22:137-151.

23 Dobbins JG, Stewart JA, Demmler GJ: Surveillance of congenital cytomegalovirus disease, 1990-1991. Collaborating registry group. MMWR CDC Surveill Summ 1992; 41:35-39.

24 Daneman A, Lobo E, Mosskin M: Periventricular band of increased echogenicity: edema or calcification? Pediatr Radiol 1998;28: 83-85.

25 Govaert P, de Vries LS: An Atlas of Neonatal Brain Sonography. London, MacKeith Press, 1997.

26 Ben-Ami T, Yousefzadeh D, Backus M, Reichman B, Kessler A, HammermanRozenberg C: Lenticulostriate vasculopathy in infants with infections of the central nervous system sonographic and Doppler findings. Pediatr Radiol 1990;20:575-579.

$\checkmark 27$ Estroff JA, Parad RB, Teele RL, Benacerraf BR: Echogenic vessels in the fetal thalami and basal ganglia associated with cytomegalovirus infection. J Ultrasound Med 1992;11: 686-688.

$28 \mathrm{Lu} \mathrm{JH}$, Emons D, Kowalewski S: Connatal periventricular pseudocysts in the neonate. Pediatr Radiol 1992;22:55-58.

29 Rademaker KJ, De Vries LS, Barth PG: Subependymal pseudocysts: ultrasound diagnosis and findings at follow-up. Acta Paediatr 1993;82:394-399. 
30 Malinger G, Lev D, Ben Sira L, Kidron D, Tamarkin M, Lerman-Sagie T: Congenital periventricular pseudocysts: prenatal sonographic appearance and clinical implications. Ultrasound Obstet Gynecol 2002;20: 447-451.

-31 Doneda C, Parazzini C, Righini A, Rustico M, Tassis B, Fabbri E, Arrigoni F, Consonni D, Triulzi F: Early cerebral lesions in cytomegalovirus infection: prenatal MR imaging. Radiology 2010;255:613-621.

32 Malinger G, Pilu G: Sonography of the central nervous system; in Rodech $\mathrm{CH}$, Whittle MJ (eds): Fetal Medicine Basic Science and Clinical Practice. London, Elsevier, 2009, vol 30.

33 Achiron R, Pinhas-Hamiel O, Lipitz S, Heiman Z, Reichman B, Mashiach S: Prenatal ultrasonographic diagnosis of fetal cerebral ventriculitis associated with asymptomatic maternal cytomegalovirus infection. Prenat Diagn 1994;14:523-526.

34 Garel C: MRI of the Fetal Brain. Normal Development and Cerebral Pathologies. Berlin, Springer, 2004.
35 Volpe JJ: Neuronal Proliferation, Migration, Organization, and Myelinization; Neurology of the Newborn. Philadelphia, Saunders, 2008, pp 51-118.

36 Malinger G, Lev D, Lerman-Sagie T: Abnormal sulcation as an early sign for migration disorders. Ultrasound Obstet Gynecol 2004; 24:704-705.

37 Hayward JC, Titelbaum DS, Clancy RR, Zimmerman RA: Lissencephaly-pachygyria associated with congenital cytomegalovirus infection. J Child Neurol 1991;6:109-114.

38 Boesch C, Issakainen J, Kewitz G, Kikinis R, Martin E, Boltshauser E: Magnetic resonance imaging of the brain in congenital cytomegalovirus infection. Pediatr Radiol 1989;19:91-93.

39 Sener RN: Schizencephaly and congenital cytomegalovirus infection. J Neuroradiol 1998;25:151-152.
40 Iannetti P, Nigro G, Spalice A, Faiella A, Boncinelli E: Cytomegalovirus infection and schizencephaly: case reports. Ann Neurol 1998;43:123-127.

41 Cohen-Sacher B, Lerman-Sagie T, Lev D, Malinger G: Developmental milestones of the fetal cerebral cortex: a longitudinal sonographic study. Ultrasound Obstet Gynecol 2006;27:494-502.

42 Dhombres F, Nahama-Allouche C, Gelot A, Jouannic JM, de Villemeur TB, Saint-Frison $\mathrm{MH}$, le Pointe HD, Garel C: Prenatal ultrasonographic diagnosis of polymicrogyria. U1trasound Obstet Gynecol 2008;32:951-954.

43 Ortiz JU, Ostermayer E, Fischer T, Kuschel B, Rudelius M, Schneider KT: Severe fetal cytomegalovirus infection associated with cerebellar hemorrhage. Ultrasound Obstet Gynecol 2004;23:402-406.

44 Lipitz S, Hoffmann C, Feldman B, Tepperberg-Dikawa M, Schiff E, Weisz B: The value of prenatal ultrasound and MR imaging in the assessment of congenital primary CMV infection. Ultrasound Obstet Gynecol 2010, E-pub ahead of print. 